Bol. Acad. peru. leng. 66. 2019 (255-263)

\title{
ASPECTOS LINGÜÍSTICOS Y SEMÁNTICOS DEL IMAGINARIO COLECTIVO LIMEÑO
}

\author{
Ana María Gispert-Sauch Colls
}

Universidad Nacional Mayor de San Marcos

Fecha de recepción:

$19 / 10 / 2019$

Fecha de aceptación:

$30 / 11 / 2019$

Nuestra sociedad limeña se caracteriza, bien lo sabemos, por su permanente transformación, no solo en cuanto a los espacios ganados al desierto y convertidos en ámbitos habitacionales, sino en sus nuevas maneras de concebir su identidad, el progreso, la «modernidad», y su ubicación en un mundo cambiante y globalizado. Los medios de comunicación masiva tienen un papel protagónico en este nuevo imaginario colectivo gestado de tradiciones y creencias ancestrales conjuntamente con los nuevos sentidos o valores que caracterizan la sociedad del siglo xxI.

Pretendo señalar algunos ejes temáticos que he encontrado sugerentes e indicativos de las nuevas imágenes que van delineándose con fuerza - y cada vez con mayor velocidad-, de las que los medios masivos dan cuenta a la vez que las alimentan.

https://doi.org/10.46744/bapl.201902.010 
Mi reflexión no pasa de ser una aproximación desde el punto de vista de los cambios semánticos o lingüísticos sobre este tema y no pretende, ni mucho menos, cubrir los artículos o expresiones aparecidos en medios de comunicación masiva, sino solamente aquellos que, a mi juicio, representan un cierto cambio de paradigmas, o bien reflejan tendencias en nuestro nuevo imaginario colectivo.

\section{El tópico de la «mujer emprendedora»}

Ya en la conjunción de ambas palabras hay un mensaje, pues no se hablaría nunca de "varón emprendedor». Eso no sería noticia. Hay un mensaje subliminal, el de que lo característico femenino no es emprender, sino aguardar en pasividad que emprendan y construyan los varones.

Em-prender. La palabra contiene una raíz y un origen feroces: conducen hacia una presa. Em-presa es vocablo de la era moderna, favorecida pronto por el capitalismo inicial europeo. La terminación -miento, en el idioma de la calle, la reservábamos hasta hace poco para la palabra desprendimiento; pero, en tiempos recientes, usamos profusamente la palabra emprendimiento (por influencia de la lengua inglesa). Debemos reconocer, sin embargo, que usamos la palabra «emprendimiento» más para los negocios menores, pues para los mayores, seguimos llamándolos «empresas» (algo semejante sucede con el uso normal del término artesanía frente al término arte). «Emprendedora» es la mujer que aparece con la aureola del «éxito». Es palabra que se aplica tanto a la mujer de extracción popular que supo sobresalir con un «negocio» como a la de la clase media-alta, que puede dirigir su propio negocio. La mujer emprendedora es la que trabaja, se las ingenia, lucha y triunfa.

Esta nueva imagen de la mujer emprendedora desplaza a un segundo plano lo que hasta hace poco se consideraba el papel propio femenino: el de la maternidad. Hay muchas mujeres exitosas que decidieron no tener hijos. La realización de la mujer como madre se va convirtiendo en una opción más, no la prioritaria. 
https://doi.org/10.46744/bapl.201902.010

La mujer —insisten los medios- ocupa cada vez más espacios de los reservados hasta ahora a los varones. Espontáneamente, nombramos en género femenino profesiones, tales como secretaria o asistenta, y ahora casi cabría decir siempre reportera, fiscal(a); pues, por alguna razón, cada vez más abundan las mujeres dedicadas a estas profesiones.

Los medios persisten en mostrar que no hay distingos ya con base en el sexo, pues hay mujeres taxistas, pilotos de los mayores aviones comerciales, astronautas etc. Últimamente, los medios invitan con regocijo a sus públicos para que se manifiesten en sus encuestas, sobre la participación de las mujeres en campos reservados exclusivamente a los varones, como es el de las funciones jerárquicas religiosas, seguros de que va a ser mayor el porcentaje de respuestas a favor de las mujeres sacerdotisas.

\section{Tiempos potenciales o impersonales}

Todos los días leemos o escuchamos la forma potencial en los verbos utilizados por los tabloides o los noticieros en sus titulares: Se haría, vendría, acabaría, construiría, renunciaría... Tiene que haber alguna razón para este abuso de la forma verbal. Similar a este es el abuso del impersonal: admiten, recomiendan, impiden, no conceden... Uno puede con razón preguntarse: ¿quiénes son los sujetos tácitos de esas acciones? Al parecer, no los hay como tampoco es válida normalmente la sustitución de las formas potenciales mencionadas por futuros, y menos aún por presentes.

Sucede simplemente que esta forma de emitir noticias (pseudonoticias, pseudoinformaciones) es mucho más cómoda, pues no compromete al emisor. Nadie podrá acusarlo de haber dado una noticia falsa; simplemente, ha extendido un rumor impalpable. Los medios fomentan así la in-cultura del «más o menos», "quién sabe», la del «dicen que», «cómo no»; así como la del «regular» o «bastante». Refuerzan la idiosincrasia de un pueblo que se resiste a contestar las preguntas con un «sí»y, más aún, con un «no». La indeterminación es más cómoda y llega a convertirse en muletilla: «se supone que...». 
Los medios en este caso fortalecen una característica (no aludo a si es positiva o negativa) de la propia identidad.

\section{Uso de apelativos en el tratamiento de personas}

La expresión de elementos y sujetos se usa solo para hacer referencia a cierto tipo de personas consideradas de nivel inferior y esconden una cierta valoración negativa. No llegan estas expresiones al extremo de la jerga militar, en la que se hablaba de números para referirse a soldados comunes de a pie, sin rango. En esas palabras, tan indefinidas —elemento, sujeto—, el emisor se ubica distante de la persona a la que se refiere: no le dice "persona», menos aún la distingue por su diferencia primaria, «mujer» o «varón», y nada se dice del nombre propio de la persona referida.

Otro apelativo es moreno. Este adjetivo calificativo hace funciones de determinativo, pues especifica en alguna de sus características, por más que somáticas, al referido. Pero, en realidad, el mensaje de los medios, cuando así nos informan sobre ciertas personas, no es en absoluto determinativo, sino pura y exclusivamente calificativo en su intención. Nunca especificarían a una persona como «amarilla» o «blanca».

El empleo de los vocablos cholo e indio no es demasiado utilizado por los medios, aunque tampoco están ausentes estas palabras. Encierran un componente racial o genético, que rara vez se libra de su carga calificativa. En todo caso, los medios deben asumir su cuota de responsabilidad en la construcción de nuestra sociedad que insiste en discriminar, y se resiste a introducir en la vida diaria el concepto de la igualdad ciudadana. Si bien hay en el pueblo expresiones que abogan por esta igualdad real, estas no se encuentran recogidas en los medios. Tales son «nadie es más que nadie», «pleitos de blancos», etc.

\section{Uso de expresiones taxativas}

En ningún lugar del mundo. En las ciencias lógicas, se enseña lo arriesgado que es lanzar una proposición universal negativa: basta con encontrar una 
https://doi.org/10.46744/bapl.201902.010

particular positiva, de signo contrario, para echarla por tierra. Aunque solo fuera por esta razón dialéctica, los promotores de opinión deberían dejar de utilizar la frase.

Pero, detrás de esa frase tan usada en los medios radiales, se esconde un mensaje: somos un país sui generis, distinto de todos. Hasta ahí no habría problema, pero sucede que la diferencia que mostramos frente a los demás países no nos favorece: el sentido de la expresión viene a ser algo así como «esto tan malo solo sucede en el Perú». Sigue en pie la inconsistencia lógica, pues habría que considerar los comportamientos de los más de 200 Estados reconocidos, pero, además, si los consideráramos, bien podemos suponer que encontraríamos comportamientos iguales y peores.

Detrás de la frase que comentamos, los medios suelen aludir a determinados países, entre los cuales figura algún Estado europeo y Chile. El mensaje se hace más claro: somos peores que otros.

Queda el terreno dispuesto para esos otros derrotismos, fatalismos y pesimismos que se expresan en frases comunes como así es aquí, somos un país pobre, hora peruana. Y la cosa se torna más grave cuando se filtra inadvertido el demostrativo este (en este país), en lugar del posesivo mi que corresponde utilizar. Bien harían los medios en cuidar las puertas por donde se filtran expresiones similares...

Paradójicamente, hay un canto patriotero, que se entona periódicamente en nuestros medios de comunicación. Quizá son los torneos futbolísticos cuando este canto se muestra con mayor evidencia. Lo curioso es que los medios acostumbran a cantar más al pasado y anunciar victorias futuras, no tanto a celebrar el presente. (Excepción de ello ha sido el éxito en la organización y celebración de los recientes juegos panamericanos y para-panamericanos con sus victorias). El efecto de este mensaje podemos advertirlo: los peruanos y limeños que desean abandonar este país y aman al Perú son — según las encuestas- la mayoría, incluso entre los comprendidos entre 35 y 45 años. Por otra parte, las celebraciones de los limeños no incluyen valses ni polkas ni se consumen en ellas los cantados dulces del lugar. 
Sí se puede. Parece un lema positivo, alentador. Lo es, pero encierra un supuesto, el de que no tenemos por necesidad que perder, como todos esperamos que suceda.

Los medios insisten en elegías y en predecirnos catástrofes. Así nos advierten que Lima quedará sedienta, que el transporte de carga va a colapsar, que el agro está en ruinas, que el patrimonio cultural no cuenta con medios para su conservación, que estamos depredando las reservas ictiológicas, que nuestro sistema educativo es lamentable, que el Seguro Social no vale... Después de estos diagnósticos negros, sobrevienen las determinaciones voluntaristas por las cuales se declaran organismos e instituciones en proceso de «completa reestructuración».

\section{Sobre la seguridad ciudadana}

A pesar de las múltiples calles enrejadas y de las campañas «calles peligrosas», y de los noticieros de televisión que advierten del cierre de locales e incluso de calles por asaltos y crímenes, la seguridad ciudadana sigue siendo el problema primordial para la mayoría de ciudadanos de Lima.

Es preocupante que más de la mitad de los limeños, según encuestas de Apoyo, crea que la población puede tomarse la justicia por las manos. Los linchamientos que se producen a menudo muestran una tendencia preocupante y significa que la institucionalidad está fallando.

Hace unas décadas, en las elecciones de las autoridades municipales, solía salir como primer reclamo el de la «recogida de basura». Los candidatos ofrecían limpiar la ciudad, conseguir para sus electores «un distrito limpio», «una Lima ordenada». En la actualidad, las encuestas sobre el problema que la ciudadanía considera más grave en Lima dan como respuesta ampliamente mayoritaria: la seguridad pública. Ya no basta la policía, los serenazgos. Los medios nos informan de convenios entre uno y otro cuerpo, los municipios editan folletos dando consejos a la ciudadanía, y esta termina optando por contratar vigilantes particulares. 
Paradójicamente, este mensaje en pro de la defensa propia está repercutiendo en la creciente formación de bandas ciudadanas, supuestamente nacidas con intención de la defensa personal y barrial (ihabla, barrio!). Lima va perdiendo así identidad ciudadana para pasar a convertirse en barrial; vamos pasando a ser un mosaico de identidades, entre las que la pertenencia a un club de fútbol no es desdeñable.

Una palabra que ha recorrido pueblos y culturas y ha valido como fórmula de expresión para los encuentros interpersonales es la palabra «salud» (del latín salve). Hasta hemos llegado a crear el verbo saludarse para esta comunicación primaria: las personas se desean mutuamente lo mejor, aquello que condicionará el resto de los bienes, la salud. Los medios van cambiando de signo este deseo fundamental. Posiblemente, por eso, cada vez se escucha más en Lima la fórmula de despedida cuídate...

\section{En torno a la corrupción}

El sustantivo «corrupción» y el adjetivo «corrupto» aparecen frecuentemente en muchos de nuestros medios escritos u orales de comunicación. Etimológicamente, viene del latín corrumpere que, a su vez, incluye el verbo «romper». Se rompen reglas o leyes de acuerdo con otros, para así obtener beneficios personales. En respuesta a esa transgresión se crean infinitas comisiones formadas, o por formar, cuya finalidad es descubrir, investigar (del latín vestigia 'ponerse sobre las huellas', estilo Sherlok Holmes...), y hacerlo en forma exhaustiva (es decir, hasta «vaciar toda el agua»). Cuando algún mal público ha sido detectado, escuchamos enseguida expresiones de este talante: «alguien tendrá que pagar», «hay que llegar hasta las últimas consecuencias» y hay que hacerlo «caiga quien caiga»... Una vez más, paradójicamente, los niveles de corrupción siguen siendo altos en la clase política nacional. Hay conciencia ciudadana de esto, la que se traduce en frases derrotistas, que uno creería ya desaparecidas pero que persisten, tales como «todos los políticos son corruptos», "yo no creo en la política», «todo es política». Como contrapartida, hay políticos que han recogido el guante e insisten en declarar su independencia con expresiones como «yo no me caso con nadie». "A mí no me tiembla 
el brazo», afirman los que tienen poder para castigar a los que sean encontrados culpables.

Los medios, la mayoría de veces, no consideran la alternativa de que haya defectos de sistema, problemas estructurales que hayan producido ese mal público lamentable. Se castiga la culpa, pero no se buscan las causas de fondo que la permiten. Una tal actuación es más cercana a la conducta conservadora que a la revolucionaria.

\section{Un «especial» puritanismo en el lenguaje escrito}

Una paradoja más de nuestros medios de comunicación es ese cierto puritanismo lingüístico, por el cual se autocensuran para no escribir o decir en público ciertas palabras que consideran «malas». Así se ven carátulas donde hay escrito $C$...., M...., P... Es una actitud semejante a la de los escolares que ocultan lisuras a su profesor. Más paradójico es aún, cuando en las mismas puritanas páginas se muestran mujeres desnudas, aparecen insultos y — mucho peor aún-se dan por ciertas informaciones no comprobadas que dañan a personas concretas.

Este grave defecto se traduce en su olvido de asuntos de importancia pública para enredarse en pleitos particulares que solo satisfacen la curiosidad o el placer morboso de husmear las vidas ajenas. Prevalece la intriga. Se fomenta así ese defecto nacional, tan reconocido y estigmatizado por tantos, de la envidia y que se ha traducido popularmente en expresiones como «trabaja y no envidies», la típica "serruchada de piso», o en el instinto que lleva a "guardar información», o la táctica de convertir al investigador en investigado, la que considera que «la mejor defensa es el ataque», etc.

\section{Expresiones particularmente afectuosas}

Si algo conmueve positivamente a un forastero cuando llega al Perú, es la acogida afectuosa que recibe, aun de desconocidos, en los pequeños diálogos de saludo, de oferta, de despedida, la mayoría expresada en los diminutivos. «Mamacita, estás cansada...»; «Mamita linda, mira 
https://doi.org/10.46744/bapl.201902.010

esto...»; «Dulcecitos ricos»...; «Qué deseas, mi amor...». Al subir o bajar de cualquier combi, además del gesto generoso de ayudar a las personas mayores, siempre acompaña una expresión como «cuídese, mamita», o «vaya con cuidado, abuelito...». En el mercado no falta la expresión "caserita, caserito...». Y en la oferta de productos no faltan los diminutivos: papitas, manzanitas, choclitos, chuletitas... Prácticamente nunca se escucha decir arvejas.

Quizás, este aspecto cariñoso, afectivo que a veces suena a irrealidad — como cuando una madre llama a su hijo o hija "papacito", «mamacita»— se deba a una visión y simbología propia del Ande, donde la persona necesita como protección a los demás, necesidad que se expresa en la «reciprocidad» tan característica del mundo andino. Lima ha ido integrando a muchos ciudadanos provenientes de los Andes y han ido creando y contagiando una cultura mucho más dulce y afectuosa que la del resto de la Costa. 